\title{
The tree-species-specific effect of forest bathing on perceived anxiety alleviation of young-adults in urban forests
}

\author{
H. Guan, H. Wei, X. He, Z. Ren, B. An
}

Guan H., Wei H., He X., Ren Z., An B., 2017. The tree-species-specific effect of forest bathing on perceived anxiety alleviation of young-adults in urban forests. Ann. For. Res. 60(2): 327-341.

Abstract. Forest bathing, i.e. spending time in a forest to walk, view and breathe in a forest, can alleviate the mental depression of visitors, but the tree-species-specific effect of this function by the urban forest is unknown. In this study, sixty-nine university students (aged 19-22, male ratio: 38\%) were recruited as participants to visit urban forests dominated by birch (Betula platyphylla Suk.), maple (Acer triflorum Komarov) and oak (Quercus mongolica Fisch. ex Ledeb) trees in a park at the center of Changchun City, Northeast China. In the maple forest only the anxiety from study interest was decreased, while the anxiety from employment pressure was alleviated to the most extent in the birch forest. Participants perceived more anxiety from lesson declined in the oak forest than in the birch forest. Body parameters of weight and age were correlated with the anti-anxiety scores. In the oak forest, female participants can perceive more anxiety alleviation than male participants. For university students, forest bathing in our study can promote their study interest. Forest bathing can be more effective to alleviate the anxiety of young adults with greater weight. The birch forest was recommended to be visited by students to alleviate the pressure of employment worry, and the oak forest was recommended to be visited by girls. Keywords natural product, psychological impact, well-being, stress, anthropogenic activities, city

Authors. Haoming Guan - Northeast Institute of Geography and Agroecology, Chinese Academy of Sciences, Changchun 130102, P.R. China \& University of Chinese Academy of Sciences, Beijing 100049, P. R. China; Hongxu Wei (weihongxu@iga.ac.cn), Xingyuan He, Zhibin Ren - Northeast Institute of Geography and Agroecology, Chinese Academy of Sciences, Changchun 130102, P.R. China; Baiyi An - College of Horticulture, Jilin Agricultural University, Changchun 130118, P.R. China.

Manuscript received October 20, 2017; revised November 20, 2017; accepted November 21, 2017; online first November 24, 2017. 


\section{Introduction}

Rapid urbanization brings not only economy and social developments but also regional changes of population, traffic, temperature and environment pollution (Pronczuka \& Surdub 2008). Although both medicine and nutrition are improved in cities, many residents still feel that their life quality is declining (Patz et al. 2005, McMichael et al. 2006, Kinney 2008, Pronczuka \& Surdub 2008). This is related to the burden of illness of current citizens and has shifted from physiological infections to non-communicable psychological anxiety disorders (Dye 2008). Urban experience contributes to tension-anxiety of citizens in nearly all ages from 10 to 60 years old (Dekker et al. 2008, McKenzie et al. 2013, Bruzzese \& Klein 2016) through shaping the socioeconomic pressure, physical environment and social interactions (Galea 2011). Results from the Global Burden of Disease Study 2013 revealed that mental and substance disorders collectively accounted for $21.2 \%$ all-year life lost to disability (YLD) wherein anxiety was ranked ninth highest specific cause of YLD in both developed and developing countries (Risal et al. 2016).

Because less than $0.01 \%$ of human-being history has been spent in urbanized society, people's philological function is still better adapted to natural ambient (Song et al. 2016). It was found that spending time in a forest can effectively reduce mental stress and alleviate anxiety (Morita et al. 2007, Kim et al. 2009, Park et al. 2011, Ochiai et al. 2015, Song et al. 2016, Chun et al. 2016). This function was recognized as the term of "forest bathing", i.e. walking, viewing and breathing in a forest (Ohtsuka et al. 1998). It has been found that forest bathing can make people feel relaxed and comfortable with more anxiety-alleviation than walking in a local urban environment (Song et al. 2013, 2014, 2015, Sonntag-Öström et al. 2015a, Chun et al. 2016). In addition, the negative mood of exhaustion-disorder and hypertensive patients was regulated by forest bathing after repeated visits for several months in the forest (Sonntag-Öström et al. 2015a, Chun et al. 2016) and mood of chronic stroke patients can be improved by 3-4 days of forest bathing (Chun et al. 2016). Taking ordinary people as participants, it was found that their anxiety can also be alleviated in 1-2 days (Park et al. 2007, 2009, 2011, Lee et al. 2009, 2014, Ochiai et al. 2015). In addition, young adults and middle-aged hypertensive patients can even perceive less anxious in a 15-min long forest bathing (Song et al. 2013, 2014, 2015). These results together suggest that forest bathing had the potential of short-term effect on anxiety of ordinary healthy people.

For visual attractiveness and high tolerance to urban stress of specific species, urban tree planting often results in uniform rows of a single species (Trowbridge \& Bassuk 2004). In an urban landscape design, the knowledge on tree parameters relevant to human perception of health-promoting enables the selection of different species which look similar (Gerstenberg \& Hofmann 2016). However, it is difficult to plan some specific tree species in an urban area with the purpose of perceived stress restoration because the motivation of tree species selection identified by residents was found to be highly related to personal preference (Conway 2016).

Quite little is known about the effect of tree-species in the urban forests on psychology of ordinary residents. University students in the age around 20 years old have been taken as subjects in studies of evaluating forest bathing effect on psychology for several times (Song et al. 2013, 2014 2015, Moran \& Moser 2015, Wang et al. 2016 ). Most undergraduates are unmarried and tend to have more anxiety disorders in the urbanized settings (Dekker et al. 2008). A large-scale study with 4000 individuals in Germany found that the impact of urbanization on anxiety was almost equal for young and elderly people. Therefore, in this study university students were recruited as participants for their self-evaluation of perceived anxiety 
in the urban forests with three different dominant tree species. Former studies found that university students can have specific response of perceived anxiety restoration to the urban environment (Stigsdotter et al. 2017). Therefore, we hypothesized that university students would also perceive varying restorations in urban forests with different dominated tree species. This study would supply a model to evaluate the tree-species effect of forest bathing on perceived anxiety allevaition. Our results can be taken as the theoretical reference to analyze anxiety alleviation in urban forests of specific tree species.

\section{Materials and methods}

\section{Study site}

This study was conducted in Changchun City $\left(43^{\circ} 05^{\prime} \sim 45^{\circ} 15^{\prime} \mathrm{N}, 124^{\circ} 18^{\prime} \sim 127^{\circ} 05^{\prime} \mathrm{E}\right)$, Jilin Province, Northeast China. Changchun City has a total area of $2.06 \times 10^{6} \mathrm{~km}^{2}$ with urban area of $7.56 \times 10^{5} \mathrm{~km}^{2}$. Annual temperature is $4.8^{\circ} \mathrm{C}$ with the range between $39.5^{\circ} \mathrm{C}$ and $-39.8^{\circ} \mathrm{C}$, average precipitation of $569 \mathrm{~mm}$, and relative humidity of $42 \%$. The study site locates at the Nanhu Park in the center of
Changchun City with the total area of 222 ha (Figure 1). About $40 \%$ area of the Nanhu Park was covered by a lake, near which three pure forests were chosen as the study plots. The birch (Betula platyphylla Suk.) forest locates in an isle in the center of Nanhu Park. The maple (Acer triflorum Komarov) and oak (Quercus mongolica Fisch. ex Ledeb) forests locate on the other side of the lake (Figure 1). Tree species were named following the classification of the International Association for Plant Taxonomy (IAPT 2012). All three forests were constructed about 20 years ago with similar characteristics (Figure 2, Table 1).

\section{Questionnaire and experimental design}

All participants were recruited from undergraduates in the major of urban horticulture from Jilin Agricultural University. Results from current studies have demonstrated that university students can fully perceive mental restoration by forest bathing in a wide range of time courses from minutes to days (Park et al. 2009, Song et al. 2013, 2014, 2015, Wang et al. 2016). Therefore, the employment of university students as subjects in our study was acceptable as the suitable sample on behalf of the larger group of population. At the

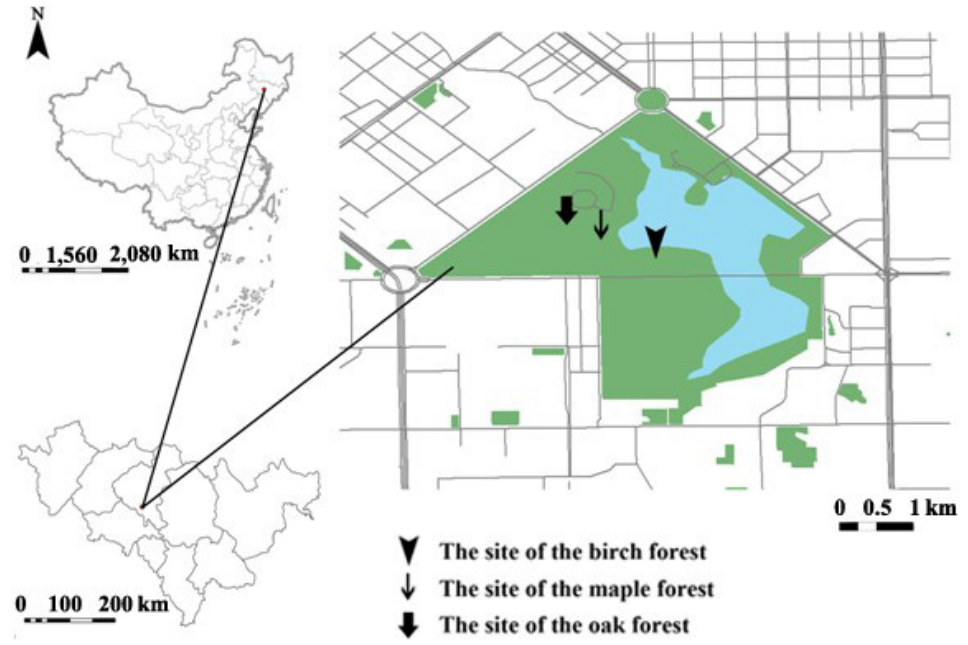

Figure 1 Locations of the study site and forest plots first-round recruitment stage, only participants free from previous diagnosed cardiovascular, allergic, or mental diseases were selected. On 9 May 2017, the day before the experimental day, first-round selected volunteers assembled to receive the full introduction about the research purpose, the experimental process, and the questionnaire procedure in the next day. Volunteers were also 
Table 1 Characteristics of dominant trees in urban forests

\begin{tabular}{llllll}
\hline Tree species & Height $(\mathrm{m})$ & $\mathrm{DBH}^{1}(\mathrm{~cm})$ & $\mathrm{CL}^{2}(\mathrm{~m})$ & $\mathrm{CD}^{3}(\%)$ & Density $\left(\right.$ stems ha $\left.^{-1}\right)$ \\
\hline Birch & $11.65 \pm 1.59^{\mathrm{ab}}$ & $13.26 \pm 0.47$ & $3.99 \pm 0.08$ & $56.43 \pm 16.13$ & $1667 \pm 145$ \\
Maple & $8.10 \pm 1.45^{\mathrm{b}}$ & $10.35 \pm 2.48$ & $3.47 \pm 1.12$ & $74.60 \pm 14.69$ & $1867 \pm 805$ \\
Oak & $12.53 \pm 1.72^{\mathrm{a}}$ & $14.39 \pm 3.01$ & $4.57 \pm 1.04$ & $77.83 \pm 2.77$ & $1933 \pm 238$ \\
$P \mathrm{r}>F$ & $\mathbf{0 . 0 3 8 8}^{4}$ & 0.1852 & 0.4077 & 0.1898 & 0.8133 \\
\hline
\end{tabular}

Note. Abbreviations: ${ }^{1} \mathrm{DBH}$ - diameter at breast height, ${ }^{2} \mathrm{CL}$ - canopy length, ${ }^{3} \mathrm{CD}$ - canopy cover rate, ${ }^{4} \mathrm{Bold}$ number indicates values significant at $P<0.05$.
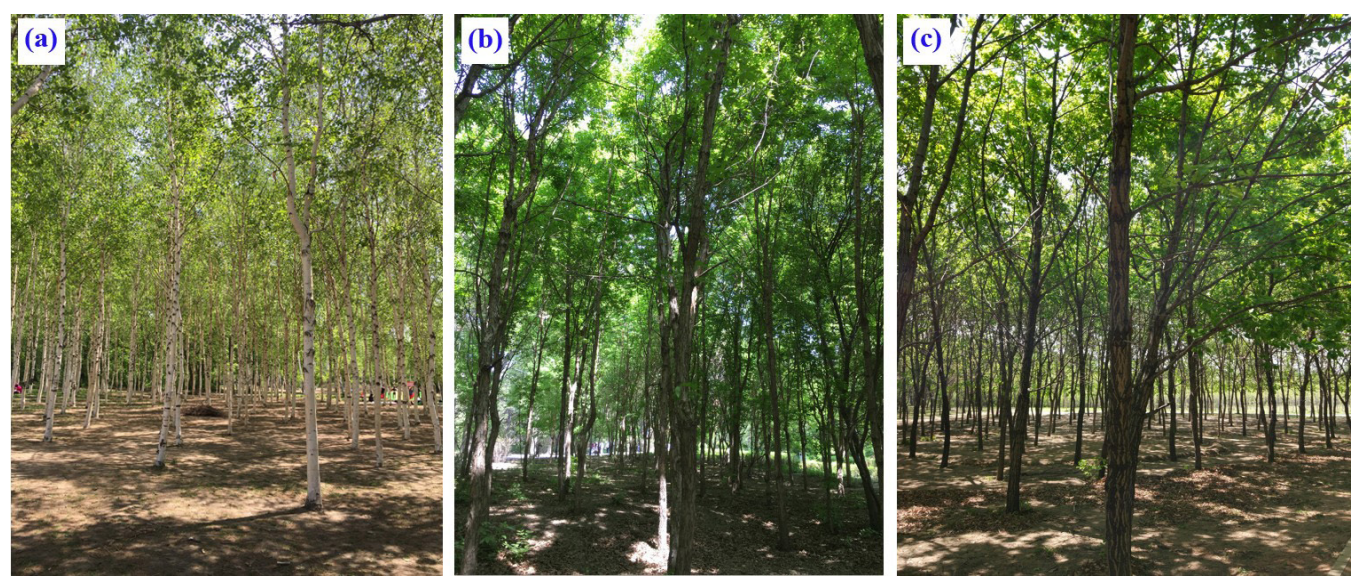

Figure 2 The under-canopy sceneries of (a) birch (Betula platyphylla Suk.), (b) maple (Acer triflorum Komarov) and (c) oak (Quercus mongolica Fisch. ex Ledeb) forests. Photo: Hongxu Wei on (10 May 2017).

informed to prohibit any of vigorous physical activity, smoking, and alcohol consumption before and throughout the whole experiment. Anyone who disagreed or unwilled to continue take part in the experiment was excluded at this stage. As a result, sixty-nine university students were selected as participants in the study. Participants were divided into three groups randomly to visit the three forests in the next day. Each group was required to contain 20-30 participants. The specific demographic characteristics of participants are shown in Table 2 .

The experiment was conducted on 10 May 2017, when it was a sunny day with cloud-cover of about $10-30 \%$. During the morning time from 8:00 to 11:00 a.m. temperature ranged between $17.6^{\circ} \mathrm{C}$ and $22.5^{\circ} \mathrm{C}$, relative humidity ranged $36-50 \%$, and the air pressure ranged 733-735 mmHg. Participants assembled in the campus of Jilin Agricultural University at 7:30 and transported to the Nanhu Park by buses in 48 min. After arrival, participants assembled again in the northeastern entrance, coded to each individual, and asked to finish the first questionnaire from 8:30 to 9:00 a.m. (Figure $3)$. Thereafter, participants walked to the three forests through a bridge, where the walking routes started to vary for different classes. After stepping down the bridge, participants in the first group walked on the road along the left lakeside, through another bridge, and reached the birch forest. During the same period, participants in the second and third groups walked 
Table 2 The demographic characteristics of participants in urban forests dominated by three tree species

\begin{tabular}{|c|c|c|}
\hline Demographic parameter & Mean & S.D. ${ }^{1}$ \\
\hline \multicolumn{3}{|c|}{$\operatorname{Birch}(n=20)$} \\
\hline Gender (male ratio) & $45 \%$ & - \\
\hline Age (years) & 22 & 1.4 \\
\hline Height $(\mathrm{cm})$ & 167.9 & 7.7 \\
\hline Weight (kg) & 58.7 & 11.9 \\
\hline $\mathrm{BMI}^{2}\left(\mathrm{~kg} \mathrm{~m}^{-2}\right)$ & 20.6 & 2.7 \\
\hline \multicolumn{3}{|c|}{ Maple $(n=23)$} \\
\hline Gender (male ratio) & $34.8 \%$ & - \\
\hline Age (years) & 21.6 & 0.9 \\
\hline Height $(\mathrm{cm})$ & 165.5 & 7.9 \\
\hline Weight (kg) & 60.4 & 14.2 \\
\hline $\mathrm{BMI}\left(\mathrm{kg} \mathrm{m}^{-2}\right)$ & 21.8 & 3.5 \\
\hline \multicolumn{3}{|c|}{ Oak $(n=26)$} \\
\hline Gender (male ratio) & $34.6 \%$ & - \\
\hline Age (years) & 21.6 & 0.9 \\
\hline Height (cm) & 166.5 & 7.3 \\
\hline Weight (kg) & 56.7 & 9.4 \\
\hline $\mathrm{BMI}\left(\mathrm{kg} \mathrm{m}^{-2}\right)$ & 20.3 & 2.2 \\
\hline
\end{tabular}

Note. Abbreviations: ${ }^{1}$ S.D. - standard deviation of a group of observations, ${ }^{2} \mathrm{BMI}$ - body mass index.

along roads through forests until the arrival of maple and oak forests, respectively (Figure 3). Thus, the first group of participants spent more time to the birch forest by about eight minutes than the other two groups to the maple and oak forests. This time is short enough to avoid the possible effect on the following perception of forest bathing (Stigsdotter et al. 2017). Participants in all three groups started to act in three forests since the same time of 10:00 a.m. Forest bathing practice included two parts of open-air class and free experience. Firstly, all participants were asked to study how to measure the forest tree characteristics for $20 \mathrm{~min}$; thereafter participants were asked to enjoy personal time in the forest area for $40 \mathrm{~min}$. In the end of free walking at 11:00 a.m., participants were asked to finish the second questionnaires with same questions of the first ones.

There were 12 questions in the questionnaire, which were separated into three classifications about topics of personal detail, school work, and social contact (Table 3) that most undergraduates in Chinese universities care about. Participants gave scores from 1 to 10 to evaluate temporally personal perception about anxiety from the aspect by the question content to quantify their self-evaluated anti-anxiety score. Each question group (every four questions) included a negative-score question to eliminate the possible subjective impact from continuously positive evaluations.

\section{Data analysis}

We used the difference of questionnaire scores between after-experiment-data and before-experiment-data to quantify the positivity score against anxiety by the Wilcoxon signed-rank test in each forest. The answers from participants in each forest were taken as replicates for the mean ( \pm standard deviation). Wilcoxon Score Rank Sum test was employed to compare the difference of scores among forests with different tree species. The significance was adjusted to be $P \leq 0.0167$ instead of $P \leq$ 0.05 by the Bonferroni correction in response to three couples of comparisons (Chi et al. 2017, Wallert et al. 2017). Self-reported scores were analyzed for their relationship with de- 


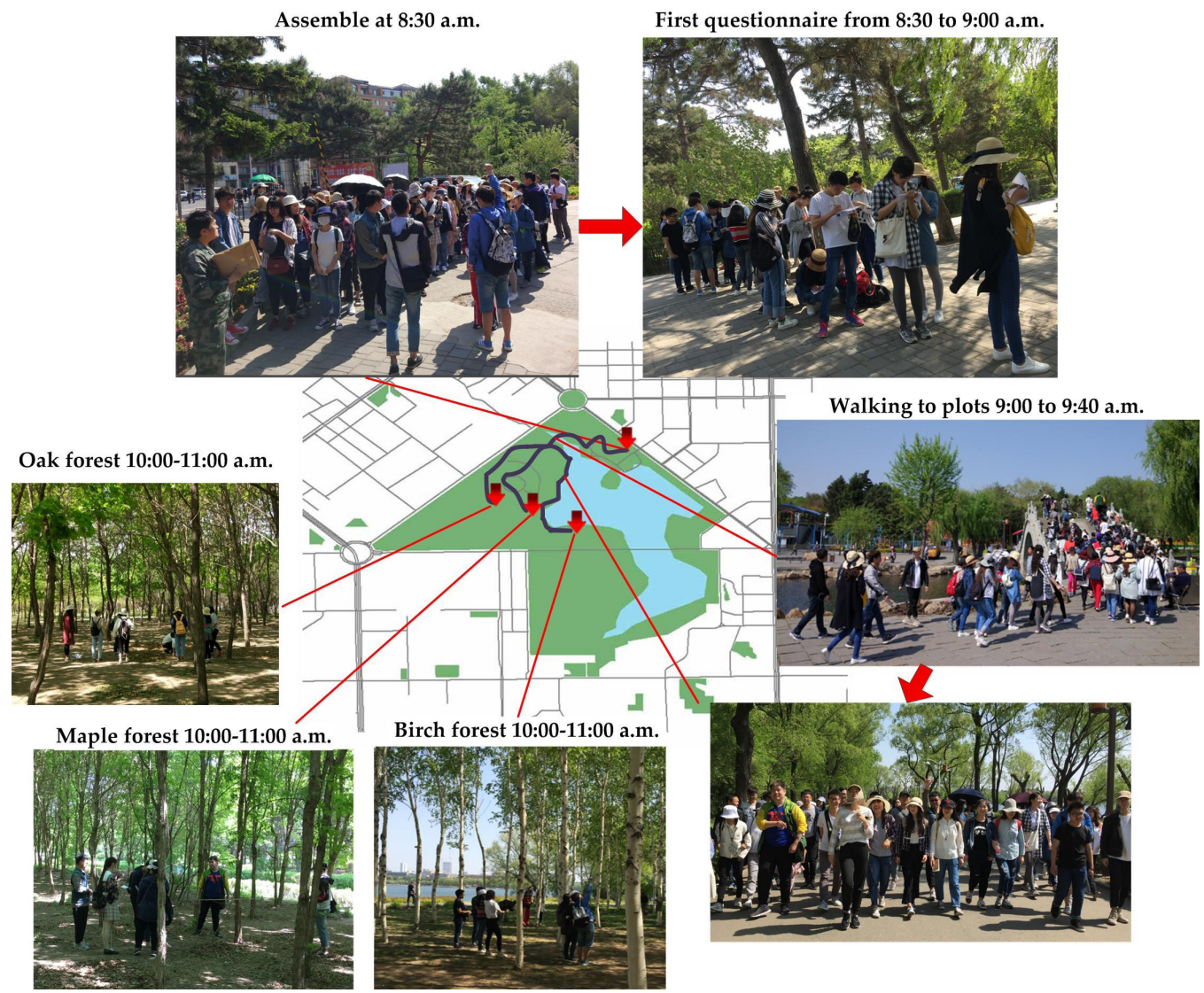

Figure 3 The process of the experiment. Twisted lines in color of dark-purple present walking routes of participants

Table 3 Details on the questionnaires used in the study

\begin{tabular}{|c|c|c|c|}
\hline $\begin{array}{l}\text { Classi- } \\
\text { fication }\end{array}$ & Topic & Specific question & $\begin{array}{l}\text { Anti- } \\
\text { anxiety }\end{array}$ \\
\hline \multirow{4}{*}{$\begin{array}{l}\text { Perso- } \\
\text { nal } \\
\text { details }\end{array}$} & Employment worry & How do you worried about your future job after graduate? & Positive \\
\hline & Graduate desire & How hard do you think to be a graduate education? & Negative \\
\hline & Finance status & How do you satisfied with your economy status? & Positive \\
\hline & Family background & How do you satisfied with your family background? & Positive \\
\hline \multirow{4}{*}{$\begin{array}{l}\text { School } \\
\text { work }\end{array}$} & Lesson satisfaction & How do you satisfied with your lesson content? & Positive \\
\hline & Teacher evaluation & How do you satisfied with your school-work teacher? & Positive \\
\hline & Study interest & How do you interested in your class study? & Positive \\
\hline & Exam-pass pressure & How much pressure do you have to pass lesson exams? & Negative \\
\hline \multirow{4}{*}{$\begin{array}{l}\text { Social } \\
\text { contact }\end{array}$} & Campus life & How do you satisfied with your campus life? & Positive \\
\hline & Communication & How hard do you think to get with others? & Negative \\
\hline & Room-mate interaction & How do you satisfied with your room-mates? & Positive \\
\hline & Love-affair relationship & How do you satisfied with your relationship status? & Positive \\
\hline
\end{tabular}


mographic data in order to detect the effect of the body trait characteristic on their anxiety-state change. In addition, to better describe multivariate relationships among variables the principal component analysis was conducted using the PINCOMP procedure. All statistical analyses were performed using SAS 9.2 TS Level 1M0 (SAS Institute Inc., Cary, NC, USA).

\section{Results}

\section{Demographic results}

There were more female participants involved in the experiment leaving the male participants to account for $34 \sim 45 \%$ of the total number of participants in each of the forests (Table 2). Age of the participants ranged between 21.6 \pm 0.9 and $22 \pm 1.4$ years old and mostly around the year of 22. Participant height appeared to be largest in the birch forest $(167.9 \pm 7.7 \mathrm{~cm})$, but weight appeared to be largest in the maple forest $(60.4 \pm 14.2 \mathrm{~kg})$. Averaged BMI for all participants were lower than 25 indicating they were generally in healthy status.

\section{Anti-anxiety scores and their variation among urban forests}

After forest bathing, most of the anti-anxiety scores tended to elevate (Figure 4). The anti-anxiety scores from three and four aspects were elevated in the birch and oak forests, respectively, but the only the score about study interest elevated in the maple forest. After bathing in the birch forest, the anti-anxiety scores from room-mate communication, study interest and personal financial state increased by about $28 \%, 17 \%$ and $11 \%$, respectively (Figure 4a). In the maple forest, the anti-anxiety score from study interest was elevated by $18 \%$ after forest bathing (Figure 4b). In the oak forest, the anti-anxiety scores from family background, campus life, lesson satisfaction, and study interest were elevated by $8 \%, 11 \%, 19 \%$ and $15 \%$, respectively (Figure 4c).

The before-and-after change between anti-anxiety scores forest bathing varied among three urban forests with different dominant trees, but only scores against anxiety from employment pressure and lesson satisfaction showed significant difference among forests (Figure 5). When the anxiety from employ pressure was questioned, the anti-anxiety score was elevated by 1.6 after forest bathing in the birch forest, which was $12\left(P=9.56 \times 10^{-4}\right)$ and three times $(P=$ $0.0033)$ of that in the maple and oak forests, respectively (Figure 5a). When the anxiety from lesson satisfaction was questioned, the anti-anxiety score was elevated by 0.25 after forest bathing in the birch forest, which was not statistically different $(P=0.5025)$ from that in the maple forest and only $20 \%(P=$ 0.0079 ) of that in the oak forest (Figure 5b).

\section{The PCA of demographical parameters on the change of anti-anxiety scores}

In all three forests, most of the demographic parameters had eigenvectors concentrated in the fourth quadrant while most anti-anxiety scores tended to have eigenvectors in the first quadrant (Figure 6). The PC-1 and PC-2 explained for about $25 \%$ and $19 \%$ of the variation in all three forests, respectively, while the PC-3 generally explained for less than 13\% of the variation (Table 4). In the birch forest the PC-1 was characterized by high loadings of teacher valuation and room-mate contact with negative loadings about lesson satisfaction, economy status, employment worry, etc (Figure 6a); the PC-2 was characterized by high loadings of nearly all psychological parameters with the negative loading of graduate desire. In the maple forest, the PC-1 was negatively loaded by the study interest while the PC-2 was negatively loaded by the love-affair 

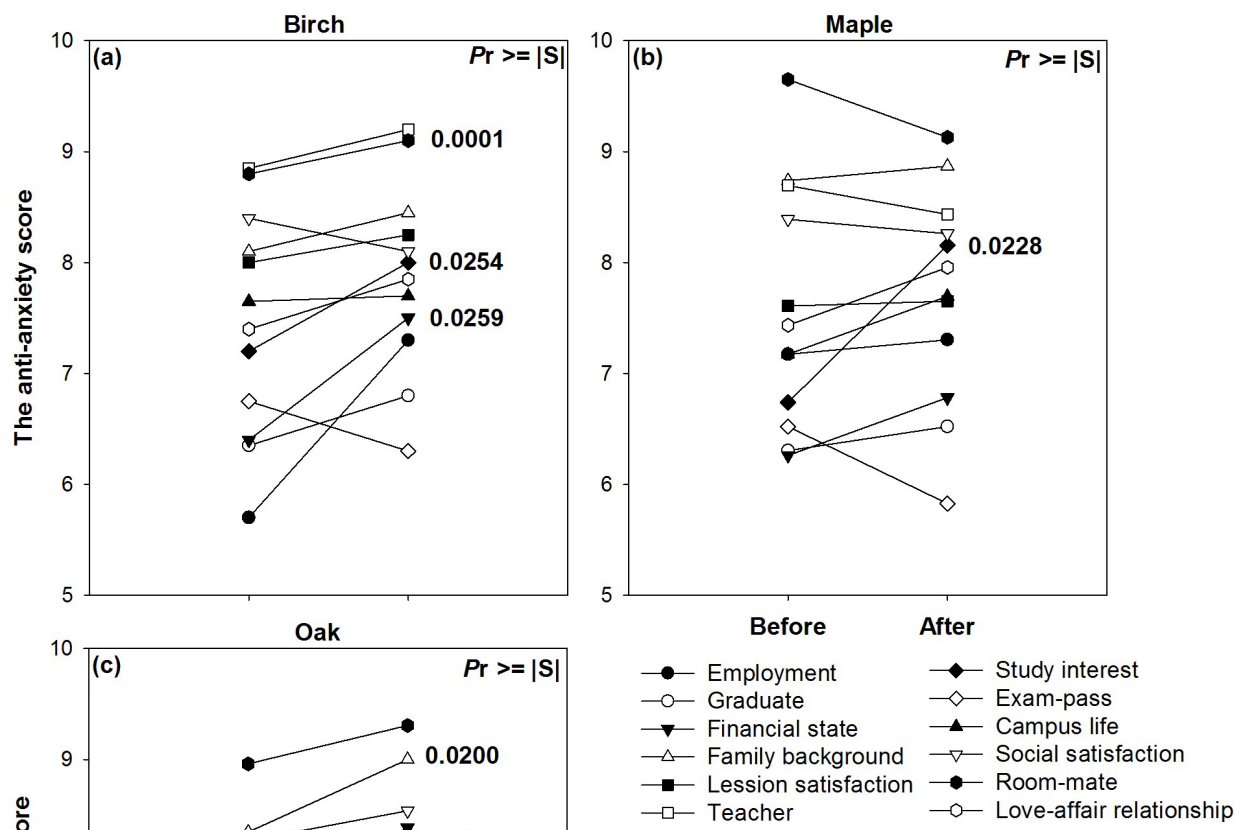

\section{Figure 4}

The anti-anxiety scores by participants evaluated before and after the forest bathing in (a) birch ( $B$. platyphylla Suk.), (b) maple (A. triflorum Komarov) and (c) oak (Q. mongolica Fisch. ex Ledeb) forests. Numbers on the right side of plots indicate significance between the two values. Numbers in bald font indicate significant difference by the Wilcoxon signed-rank test ( $a=0.05$ ).

relationship and family background (Figure 6b). In the oak forest, the PC-1 was negatively loaded by the social communication and the PC-2 was characterized by positive loadings of all psychological parameters (Figure 6c).

In the PC-1 axis of birch forest, body parameters of BMI, height and weight were accompanied by more anxiety alleviation from inter-communications with room-mate and teacher, but with low anti-anxiety scores from lesson content (Figure 6a). In the PC-2 axis, the parameter of gender was accompanied by lower anti-anxiety scores from about $2 / 3$ of all aspects (Figure 6a). This suggested that female participants tended to perceive less anxiety restoration than male participants.

In the maple forest, the body parameters of weight and height were accompanied by higher scores of anti-anxiety from several aspects, such as communications with family background and love-affair relationship (Figure $6 \mathrm{~b})$. In the PC-2 axis, however, body parameters of weight and BMI were accompanied by less alleviation of anxieties from room-mate contact and teacher evaluation (Figure 6b).

In the oak forest, parameters of gender and age were accompanied by more alleviation of most of the anxiety aspects from the university 

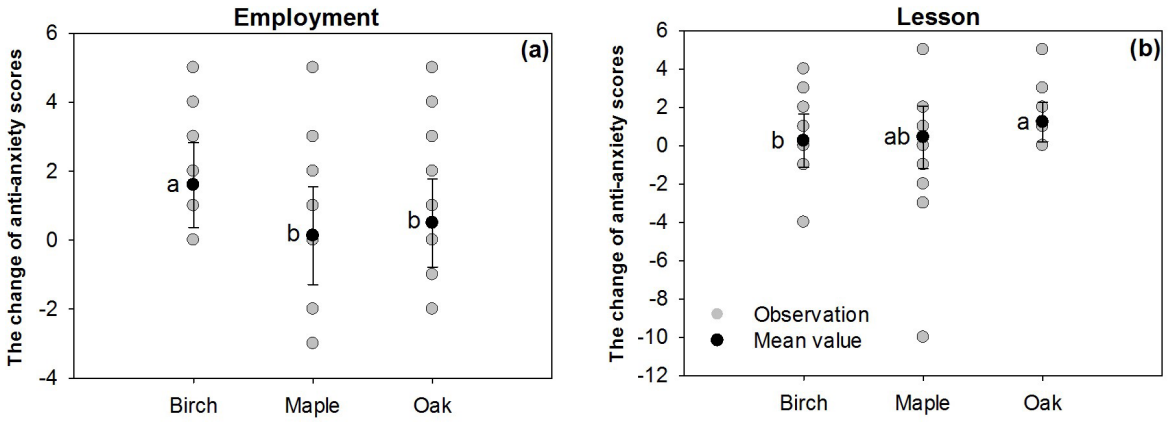

Figure 5 The after-before changes of anti-anxiety scores from employment pressure (a) and lesson satisfaction (b) in birch (B. platyphylla Suk.) $(n=20)$, maple (A. triflorum Komarov) $(n=23)$ and oak (Q. mongolica Fisch. ex Ledeb) $(n=26)$ forests. Dotted plots in light grey present observations by each participant. Plots in black present the mean values with error bars of standard deviations. Different letters beyond the plots indicate significant difference by the Wilcoxon Score Rank Sum test at the 0.0167 level adjusted by the Bonfferoni correction.

affairs in the PC-1 axis, such as lesson satisfactory, room-mate contact, and the examination pressure (Figure 6c). In the PC-2 axis, however, the body parameters of height and weight were accompanied by lower scores of anti-anxiety scores from social communications (Figure 6c).

\section{Discussion}

\section{The employment of spring time in May}

In our study, the experiment was conducted in 10 May, when it was a typically sunny day in spring of Northeast China. This day fell in the spring period with increasing temperature and elongating daylight when phenology started at the initial blooming but air temperature had not been so high to make people feel uncomfortable. Although university students can also perceive mental restoration in an urban forest in fall (Song et al. 2015b) and winter (Song et al. 2013), more studies demonstrated the perceived response to forest bathing in spring (Ohtsuka et al. 1998, Song et al. 2014, Sonntag-Öström et al. 2015b). Ohtsuka et al. (1998) considered that the numerous negative ions in the forest in spring gave people a feeling of refreshment and exposure to negative ions can enhance parasympathetic nervous activity and decrease blood glucose levels. Sonntag-Öström et al. (2015b) argued that the overall evaluation of mental state during the spring showed a greater effect on well-being compared with those during the autumn, which mainly resulted from the daylight elongation in spring. Gerstenberg \& Hofmann (2016) found that the full expansion of leaves in spring enabled the full perception in response to the tree features. In an integrated summary, Song et al. (2016) concluded that forest bathing in spring has several benefits for well-being, such as increases in parasympathetic nervous activity, inhibitions in sympathetic nervous activity, and decreases in the heart rate, thereby resulting in the physiological relaxation effect. All these aspects may all contribute to the significant results in our study by a spring-time experiment. In addition, Park et al. (2011) reported that perception was sensitive to the high air temperature in the urban environment, which may be alleviated by the urban forest atmosphere in spring in our study. 

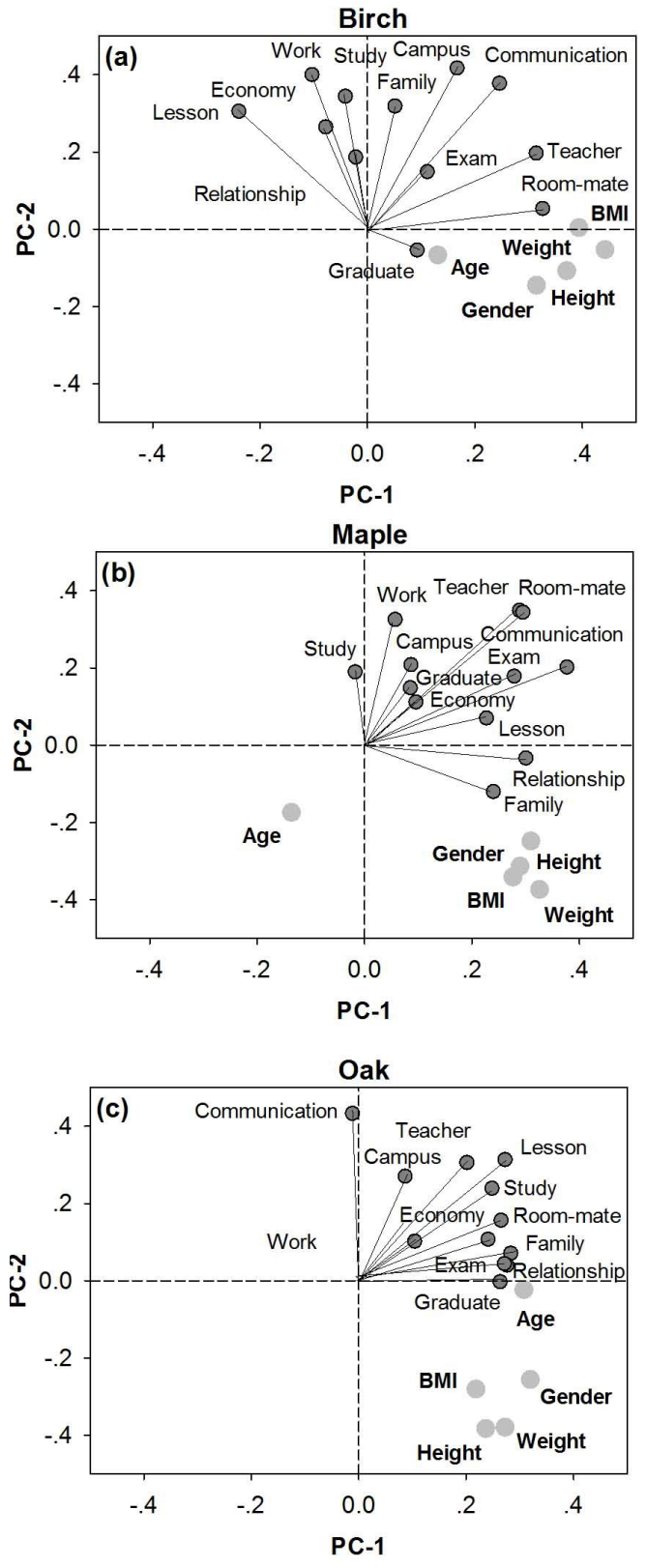

The tree-species significance in after-and-before effect of forest bathing on anxiety alleviation

Our study found that young adults can perceive the anxiety alleviation in all three forests (Figure 4). Given the fact that the tree species in our study were broad-leafed, we consider that there may exist some tree-species significance in the effect of forest bathing on perceived anxiety alleviation. Although few studies have focused on this issue, studies about forest bathing suggested that the significant effect on mental restoration also accompanied by hard-wood species of oak (Park et al. 2007, Lee et al. 2009, 2014, Han et al. 2016) and maple (Lee et al. 2014, Song et al. 2015b, Han et al. 2016). In addition, more studies suggested that the forest bathing effect on anxiety alleviation was accompanied by coniferous tree species, such as Japanese cypress (Chamaecyparis obtusa) (Lee et al. 2014, Song et al. 2015a, Zhang et al. 2015, Song et al. 2016) and pine (Pinus spp.) (Sonntag-Öström et al. 2015a, b, Chun et al. 2016, Han et al. 2016). However, very little evidence can be found about the perceived anxiety by participants in the birch forest. In our study, the significant effect of forest bathing among birch trees on anxiety decline may originate from their surface appearance. Studies have indicated that the white color of the surround settings can result in more perceived anxiety decline by mices (Sherwin \& Glen 2003). Therefore, the white bark color of birch trees may have partly contributed to the perception significance. We also noted that the stem density of birch trees tended to the lower than oak and maple, which may allow more sunlight to penetrate through the crowns and

Figure 6 The principal component analysis of demographic parameters on changes of anti-anxiety scores of participants before and after they went into (a) the birch (B. platyphylla Suk.), (b) maple (A. triflorum Komarov) and (c) oak (Q. mongolica Fisch. ex Ledeb) forests. Abbreviations accordingly to Table 3: Work - employment, Graduate - graduate desire, Economy - finance status, Family family background, Lesson - lesson satisfaction, Teacher - teacher evaluation, Study - study interest, Exam - exam-pass pressure, Campus - campus life, Communication - social communication, Room-mate - room-mate interaction, Relationship - love-affair, relationship. 
Table 4 Description of the main components in PCA

\begin{tabular}{llllll}
\hline Forests & Principal component & Eigenvalue & Difference & Proportion (\%) & Accumulative (\%) \\
\hline Birch & 1 & 4.1894 & 1.2979 & 24.64 & 24.64 \\
& 2 & 2.8915 & 0.6885 & 17.01 & 41.65 \\
& 3 & 2.2030 & 0.2881 & 12.96 & 54.61 \\
Maple & 1 & 4.2948 & 0.8265 & 25.26 & 25.26 \\
& 2 & 3.4683 & 1.3226 & 20.40 & 45.67 \\
& 3 & 2.1457 & 0.5188 & 12.62 & 58.29 \\
Oak & 1 & 5.2418 & 2.1249 & 30.83 & 30.83 \\
& 2 & 3.1169 & 1.4478 & 18.33 & 49.17 \\
& 3 & 1.0091 & 0.1717 & 3.02 & 52.19 \\
\hline
\end{tabular}

strengthened the white-color perception (Table 2a). Gerstenberg \& Hofmann (2016) demonstrated that crown shape and the crown density were important parameters mirroring human preference. In our study we have no idea yet to know whether the crown features contributed to the significance of perceived anxiety decline in the birch forest, but we suggest more work in the future to prove our results with more detailed evidence.

\section{The difference of perceived anxiety allevia- tion among forests}

We found that participants in the three forests perceived alleviation of different anxieties. After forest bathing in the birch and oak forests, participants perceived several anxieties were alleviated covering all aspects of the anxious mood. However, in the maple forest only one aspect of anxiety declined. The possible explanation being responsible for the poor perceived response in the maple forest may be related to the darker color in the maple forest. Studies have found that people perceived darker conditions as more enclosed and, therefore, less favorable due to insufficient perception of safety (Stamps 2010, Sonntag-Öström et al. 2015b). The dark color of barks in maple trees can be responsible for the dark setting color, but the lowest tree height and moderate crown density and stem density may also impact the sunlight penetration. In contrast to our results, in other regions maple trees were reported to account for the highest ecological and aesthetic benefits in the urban forest (Millward \& Sabir 2011). It is necessary to detect the perceived response to more maple forests with various maple tree features in the urban environment so as to determine the best strategy of their management.

Thus, oak and maple are usually planted together to generate the landscape in promoting perceived stress alleviation (Lee et al. 2014, Han et al. 2016). This concurs with our results about the difference between the oak and maple forests in the effect on anxiety perceptions for the employment worry and lesson satisfactory. However, both oak and maple forests resulted in less perceived anxiety alleviation from employment than the birch forest. This may be caused by the visional view in the birch forest with easily accessible, open and bright settings with visible lake, which were all evaluated to be very attractive to visitors (Sonntag-Öström et al. 2015b, Zhang et al. 2015). Students may worry about their employment in the future before they went into the birch forest, but the forest bathing with specific view during their following minutes may have decreased some of the worry. In contrast, participants perceived anxiety alleviation in the oak forest with higher lesson satisfaction than in the birch and maple forests, which may also be the result of surround settings. In the oak forest, participants were relatively further 
from the lake and the view was narrow, which may cause their attention to the lesion study in the forest because participants were from the major of horticulture.

Participants perceived that their anxiety from study interest was alleviated significantly in all three forests. Because participants were recruited as university students from the major of urban horticulture, to know and study the scenery of urban forest is one of their course missions. Participants had studied the method, theory and mechanism of urban forest evaluation in the university campus. During the experiment, however, the experience of forest bathing enhanced their study interest therefore decreased anxiety. In a survey in the Society of American Foresters, respondents consider that urban forestry is well accepted as a community of interest which can confer them more perception of pleasure and love of the city than hates (Ricard \& McDonough 2007). Future work is suggested to detect the perceived anxiety alleviation by participants of a wider population group especially those with little professional knowledge about forest.

\section{Demographic determinants of anxiety}

In our study, anlysis of PCA indicated the similar results in each of the forests but different relationship between anxiety and demographic parameters among the three forests. In the birch forest, participants with greater weight perceived more alleviation of anxieties about teacher satisfaction and social communication (Table 5). We found that body weight was the parameter that had positive relationship with alleviation of most of the anxieties from campus life and inter-communications. For example, in the birch forest participants with greater weight perceived more pleasure to communicate with teacher and room-mates while in the oak forest, heavier participants tended to feel more confidence to pass examination, thereafter they perceived more anxiety alleviation. These results concur with those from the forest bathing effect on perceived anxiety alleviation in birch and oak forests (Figure 1). However, in the oak forest female participants with greater weight perceived more alleviation of anxiety from personal details and social communication. This disagrees with the results found by Simsek et al. (2015), where there was a negative correlation between weight-driven BMI and social cognition in girls. This may be the result by the effect from forest bathing in oak trees. Giving the results that no correlation between gender and anxiety was found in the birch and maple forests, the negative effect of weight on social communication was alleviated in the oak forest. In the maple forest, participants with greater weight perceived more alleviation of anxieties about family background and love-affair relationship, suggesting that heavier participants perceived more about family affairs. In the maple forest, younger participants would more like to communicate with the teacher hence perceived more anxiety alleviation probably because they asked lots of questions about the measuring method and result precision in the maple forest. Examination pressure was found to be the major source of anxiety of university students (Alzahem et al. 2011). Although forest bathing was found to be insufficient to alleviate the anxiety from exam-pass pressure, in the oak forest younger participants perceived more anxiety from exam-pass pressure. Therefore, the experience in the oak forest can be more effective to alleviate anxiety from exam-pass pressure in elder university students.

\section{Current limits and future perspectives}

In our study we found a significant tree-species-specific effect of forest bathing on anxiety alleviation. However, our results were still limited by the number of species, psychological mechanism and physiological responses. Therefore, we suggest future works can concern more details in such perspectives. Firstly, coniferous tree species, e.g. cypress and pine, 
were not considered in our study despite the fact that they are popularized in urban forests. Based on current findings, there should be some significant effect of forest bathing between coniferous and broad-leaf species on perceived anxiety alleviation. Secondly, future studies are suggested to care more about the mechanism for the establishment of species-specific effect on psychology. Aspects of tree color, canopy shape, smell and the possibly touch feeling all need much more details to clarify the effect of forest bathing. Finally, future works are also suggested to quantify the physiological response to urban forests with different dominant tree species. Relevant evidence has been abundant in studies comparing forest and urban environments.

\section{Conclusions}

Our study found that urban forest had a tree-species-specific effect on anxiety alleviation in university students. In both birch and oak forests participants can perceive significant alleviation of anxieties about personal details, school work and social contact, but in the maple forest only anxiety from study interest was perceived to decline. In the birch forest participants perceived more anxiety from employment pressure to be alleviated than in the maple and oak forests. Therein participants with greater body weight can perceive more pleasure of communication with the teacher. In the oak forest participants perceived more anxiety alleviation from lesson satisfaction than in the birch forest. Heavier and elder participants perceived more anxiety from exam-pass pressure. In conclusion, for university students, forest bathing in our study can promote their study interest. Forest bathing can be more effective to alleviate the anxiety of young adults with greater weight. The birch forest was recommended to be visited by students to alleviate the pressure of employment worry, and the oak forest was recommended to be visited by girls.

\section{Acknowledgments}

This study was supported by the National Natural Science Foundation of China (31600496) and The National Key Research and Development Program of China (2016YFC0500307).

\section{References}

Alzahem A.M., van der Molen H.T., Alaujan A.H., Schmidt H.G., Zamakhshary M.H., 2011. Stress amongst dental students: a systematic review. European Journal of Dental Education 15:8-18. DOI: $10.1111 / \mathrm{j} .1600-0579.2010 .00640 . x$.

Bruzzese J.M., Klein R.G., 2016. The association of youth and caregiver anxiety and asthma care among urban young adolescents. Academic Pediatrics 16:792-798. DOI: 10.1016/j. acap.2016.03.009.

Chi X.L., Guo Q., Fang J.Y, Schmid B., Tang Z.Y., 2017. Seasonal characteristics and determinants of tree growth in a Chinese subtropical forest. Journal of Plant Ecology 10:4-12. DOI: 10.1093/ jpe/rtw051.

Chun M.H., Chang M.C., Lee S.J., 2016. The effects of forest therapy on depression and anxiety in patients with chronic stroke. International Journal of Neurosciences 1. DOI: 10.3109/00207454.2016.1170015.

Conway T.M., 2016. Tending their urban forest: Residents' motivations for tree planting and removal. Urban Forestry and Urban Greening 17:23-32. DOI: 10.1016/j.ufug.2016.03.008.

Dekker J., Peen J., Koelen J., Smit F., Schoevers, R., 2008. Psychiatric disorders and urbanization in Germany. BMC Public Health 8:17. DOI: 10.1186/1471-2458-8-17.

Dye C., 2008. Health and urban living. Science, 319:766-769. DOI: 10.1126/science.1150198.

Galea S., 2011. The urban brain: new directions in research exploring the relation between cities and mood-anxiety disorders. Depression and Anxiety 28:857-862. DOI: 10.1002/da.20868.

Gerstenberg T., Hofmann M., 2016. Perception and preference of trees: A psychological contribution to tree species selection in urban areas. Urban Forestry and Urban Greening 15:103-111. DOI: 10.1016/j.ufug.2015.12.004.

Han J.W., Choi H., Jeon Y.H., Yoon C.H., Woo J.M., Kim W., 2016. The effects of forest therapy 
on coping with chronic widespread pain: Physiological and psychological differences between participants in a forest therapy program and a control group. International Journal of Environmental Research and Public Health 13:255. DOI: 10.3390/ijerph13030255.

IAPT, 2012. International Code of Nomenclature for algae, fungi, and plants (Melbourne Code) Web:http://www.iapt-taxon.org/nomen/main. php. Accessed: 10.2017

Kim W., Lim S.K., Chung E.J., Woo J.M., 2009. The effect of cognitive behavior therapy-based psychotherapy applied in a forest environment on physiological changes and remission of major depressive disorder. Psychiatry Investigation 6:245254. DOI: 10.4306/pi.2009.6.4.245.

Kinney P.L., 2008. Climate change, air quality, and human health. American Journal of Preventive Medicine 35:459-467. DOI: 10.1016/j.amepre.2008.08.025.

Lee J.Y., Park B.J., Tsunetsugu Y., Kagawa T., Miyazaki Y., 2009. Restorative effects of viewing real forest landscapes, based on a comparison with urban landscapes. Scandinavian Journal of Forest Research 24:227-234. DOI: 10.1080/02827580902903341.

Lee J.Y., Tsunetsugu Y., Takayama N., Park B-J., Li Q., Song C., Komatsu M., Ikei H., Tyrväinen L., Kagawa T., Miyazaki Y., 2014. Influence of forest therapy on cardiovascular relaxation in young adults. Evidence-Based Complementary and Alternative Medicine 834360. DOI: $10.1155 / 2014 / 834360$.

Li Q., Morimoto K., Nakadai A., Inagaki H., Katsumata M., Shimizu T., Hirata Y., Hirata K., Suzuki H., Miyazaki Y., Kagawa T., Koyama Y., Ohira T., Takayama N., Krensky A.M., Kawada T., 2007. Forest bathing enhances human natural killer activity and expression of anti-cancer proteins. International Journal of Immunopathological Pharmacology 20:3-8. DOI: 10.1177/03946320070200S202.

McKenzie K., Murray A., Booth T., 2013. Do urban environments increase the risk of anxiety, depression and psychosis? An epidemiological study. Journal of Affective Disorders 150:1019-1024. DOI: 10.1016/j.jad.2013.05.032.

McMichael A.J., Woodruff R.E., Hales S., 2006. Climate change and human health: present and future risks. Lancet 367. 859-869. DOI: 10.1016/ S0140-6736(06)68079-3.

Millward A.A., Sabir S., 2011. Benefits of a forested urban park: What is the value of Allan Gardens to the city of Toronto, Canada? Landscape and Urban Planning 100:177-188. DOI: 10.1016/j. landurbplan.2010.11.013.

Moran T.P., Moser J.S., 2015. The color of anxiety: Neurobehavioral evidence for distraction by perceptually salient stimuli in anxiety. Cognitive, Affective, \& Behaviorial Neuroscience 15:169-179. DOI: 10.3758/s13415-014-0314-7.

Morita E., Fukuda S., Nagano J., Hamajima N., Yamamoto H., Iwai Y., Nakashima T., Ohira H., Shirakawa T., 2007. Psychological effects of forest environments on healthy adults: Shinrin-yoku (forest-air bathing, walking) as a possible method of stress reduction. Public Health 121:54-63. DOI: 10.1016/j.puhe.2006.05.024.

Ochiai H., Ikei H., Song C., Kobayashi M., Miura T., Kagawa T., Li Q., Kumeda S., Imai M., Miyazaki Y., 2015. Physiological and Psychological effects of a forest therapy program on middle-aged females. International Journal of Environmental Research and Public Health 12:15222-15232. DOI: $10.3390 /$ ijerph121214984.

Ohtsuka Y., Ybunaka N., Takayama S., 1998. Shinrin-yoku (forest-air bathing and walking) effectively decreases blood glucose levels in diabetic patients. International Journal of Biometeorology 41:125-127. DOI: 10.1007/s004840050064.

Park B.J., Tsunetsugu Y., Kasetani T., Hirano H., Kagawa T., Sato M., Miyazaki Y., 2007. Physiological effects of Shinrin-yoku (taking in the atmosphere of the forest) - using salivary cortisol and cerebral activity as indicators. Journal of Physiological Anthropology 26: 123-128. DOI: 10.2114/jpa2.26.123.

Park B.J., Tsunetsugu Y., Kasetani T., Morikawa T., Kagawa T., Miyazaki Y., 2009. Physiological effects of forest recreation in a young conifer forest in Hinokage Town, Japan. Silva Fennica 43:291-301. DOI: 10.14214/sf.213.

Park B.J., Furuya K., Kasetani T., Takayama N., Kagawa T., Miyazaki Y., 2011. Relationship between psychological responses and physical environments in forest settings. Landscape and Urban Planning 102: 24-32. DOI: 10.1016/j.landurbplan.2011.03.005.

Patz J.A., Campbell L.D., Holloway T., Foley J.A., 2005. Impact of regional climate change on human health. Nature 438: 310-317. DOI: 10.1038/ nature 04188 .

Pronczuka J., Surdub S., 2008. Children's environmental health in the twenty-first century. Annals 
of the New York Academy of Sciences 1140(1): 143-154. DOI: 10.1196/annals.1454.045.

Richard R.M., McDonough M.H., 2007. What do foresters think about urban forestry, urban people, and cities? Journal of Forestry 105:285-292.

Risal A., Manandhar K., Linde M., 2016. Anxiety and depression in Nepal: prevalence, comorbidity and associations. BMC Psychiatry 16:102. DOI: 10.1186/s12888-016-0810-0.

Sherwin C.M., Glen E.F., 2003. Cage colour preferences and effects of home cage colour on anxiety in laboratory mice. Animal Behaviour 66: 10851092. DOI: 10.1006/anbe.2003.2286.

Simsek T.T., Turkucuoglu B., Tezcan S., 2015. Examination of the relationship between body mass index (BMI) and functional independence level in children with spina bifida. Developmental Neurorehabilitation 18:149-154. DOI: 10.3109/17518423.2013.796419.

Song C., Joung D., Ikei H., Igarashi M., Aga M., Park BJ., Miwa M., Takagaki M., Miyazaki Y., 2013. Physiological and psychological effects of walking on young males in urban parks in winter. Journal of Physiological Anthropology 32:18. DOI: $10.1186 / 1880-6805-32-18$.

Song C., Ikei H., Igarashi M., Miwa M., Takagaki M., Miyazaki Y., 2014. Physiological and psychological responses of young males during spring-time walks in urban parks. Journal of Physiological Anthropology 33: 8. DOI: 10.1186/1880-6805-33-8.

Song C., Ikei H., Kobayashi M., Miura T., Taue M., Kagawa T., Li Q., Kumeda S., Imai M., Miyazaki Y., 2015a. Effect of forest walking on autonomic nervous system activity in middle-aged hypertensive individuals: A pilot study. International Journal of Environmental Research Public Health 12: 2687-2699. DOI: 10.3390/ijerph120302687.

Song C., Ikei H., Igarashi M., Takagaki M., Miyazaki Y., 2015b. Physiological and Psychological effects of a walk in urban parks in fall. International Journal of Environmental Research and Public Health 12: 14216-14228. DOI: 10.3390/ ijerph121114216.

Song C., Ikei H., Miyazaki Y., 2016. Physiological effects of nature therapy: A review of the research in Japan. International Journal of Environmental Research and Public Health 13: 781. DOI: 10.3390/ijerph13080781.

Sonntag-Öström E., Stenlund T., Nordin M.,
Lundell Y., Ahlgren C., Fjellman-Wiklund A., Järvholm LS., Dolling A., 2015a. "Nature's effect on my mind" - Patient's qualitative experiences of a forest-based rehabilitation programme. Urban Forestry and Urban Greening 14: 607-614. DOI: 10.1016/j.ufug.2015.06.002.

Sonntag-Öström E., Nordin M., Dolling A., Lundell Y., Nilsson L., Järvholm L.S., 2015b. Can rehabilitation in boreal forests help recovery from exhaustion disorder? The randomised clinical trial ForRest. Scandinavian Journal of Forest Research 30: 732-748. DOI: 10.1080/02827581.2015.1046482.

Stigsdotter UK., Corazon SS., Sidenius U., Kristiansen J., Grahn P., 2017. It is not all bad for the grey city - A crossover study on physiological and psychological restoration in a forest and an urban environment. Health \& Place 46: 145-154. DOI: 10.1016/j.healthplace.2017.05.007.

Sung J., Woo JM., Kim W., Lim SK., Chung EJ., 2012. The effect of cognitive behavior therapy-based "forest therapy" program on blood pressure, sali-vary cortisol level, and quality of life in elderly hypertensive patients. Clinical and Experimental Hypertension 34:1-7. DOI: 10.3109/10641963.2011.618195.

Trowbridge PJ., Bassuk NL., 2004. Trees in the urban landscape: Site assessment, design, and installation. Wiley: Hoboken, New Jersey, USA.

Tsunetsugu Y., Park BJ., Miyazaki Y., 2010. Trends in research related to "Shinrin-yoku" (taking in the forest atmosphere or forest bathing) in Japan. Environmental Health and Preventive Medicine 15: 27-37. DOI: 10.1007/s12199-009-0086-9.

Wallert J., Tomasoni M., Madison G., Held C., 2017. Predicting two-year survival versus non-survival after first myocardial infarction using machine learning and Swedish national register data. BMC Medical Informatics and Decision Making 17: 99. DOI: 10.1186/s12911-017-0500-y.

Wang XX., Rodiek SS., Wu CZ., Chen Y., Li Y.X., 2016. Stress recovery and restorative effects of viewing different urban park scenes in Shanghai, China. Urban Forestry and Urban Greening 15: 112-122. DOI: 10.1016/j.ufug.2015.12.003.

Zhang T., Deng SQ., Ma QQ., Sasaki K., 2015. Evaluations of landscape locations along trails based on walking experiences and distance traveled in the Akasawa forest therapy base, central Japan. Forests 6: 2853-2878. DOI: 10.3390/f6082853. 